\title{
ESCRITA E GRAMÁTICA COMO TECNOLOGIAS URBANAS: A CIDADE NA HISTÓRIA DAS LÍNGUAS E DAS IDEIAS LINGUÍSTICAS
}

\author{
CAROLINA RODRÍGUEZ-ALCALÁ ${ }^{1}$
}

\begin{abstract}
RESUMO: Este texto propõe relacionar a história da língua e do conhecimento linguístico à história da cidade, através da caracterização de tecnologias como a escrita, a gramática e o dicionário enquanto tecnologias urbanas. Procuramos indicar, de um lado, a coincidência histórica que é possível constatar entre os processos de gramatização e de urbanização, a través de um breve percurso por momentos chaves da história de Ocidente: a invenção da escrita, o surgimento da gramática greco-latina na Antiguidade, sua transferência como modelo de descrição para todas as línguas do mundo a partir do Renascimento europeu e a gramatização brasileira do português no século XIX. De outro lado, queremos mostrar que a elaboração e a transferência dessas tecnologias são indissociáveis de um imaginário da escrita e do urbano, inscrito numa memória da permanência - dos sujeitos e das línguas - , que incide nas relações políticas estabelecidas tanto entre as sociedades como no interior das mesmas. A partir da leitura de alguns documentos dos jesuítas, analisaremos de que modo esse imaginário agiu na colonização no Brasil, orientando o trabalho de instrumentação das línguas indígenas e dos novos espaços conquistados pelos portugueses e conformando relações de força particulares com seus habitantes. Assinalaremos, finalmente, como essas relações se projetaram no tempo na nova sociedade constituída, já no contexto da gramatização do português vinculada à consolidação do Estado nacional independente, em que esse imaginário que estruturara num primeiro momento a relação entre europeus e índios passou a afetar a relação entre brasileiros e brasileiros, significados de acordo com sua inscrição no espaço (urbano/não urbano) e o domínio dessas tecnologias (letrados/iletrados).
\end{abstract}

Palavras-chaves: escrita, gramática, cidade.

RESUMEN: Este texto propone relacionar la historia de la lengua y del conocimiento lingüístico con la historia de la ciudad, a través de la caracterización de tecnologías como la escritura, las gramáticas y los diccionarios en cuanto tecnologías urbanas. Buscamos indicar, de un lado, la coincidencia histórica que podemos constatar entre los procesos de gramatización y de urbanización, a través de un breve recorrido por momentos claves de la historia de Occidente: la invención de la escritura, el surgimiento de la gramática grecolatina en la Antigüedad, su transferencia como modelo de descripción para todas las lenguas del mundo a partir del Renacimiento europeo y la gramatización brasilera del portugués en el siglo XIX. Por otro lado, queremos mostrar que la elaboración y transferencia de tales tecnologías son indisociables de un imaginario de la escritura y de lo urbano, inscrito en una memoria de la permanencia - de los sujetos y de las lenguas —, que incide en las relaciones políticas establecidas tanto entre las sociedades cómo en el interior de las mismas. A partir del análisis de algunos documentos de los jesuitas, analizaremos de qué modo ese imaginario intervino en la colonización del Brasil, orientando el trabajo de instrumentación de las lenguas indígenas y de los nuevos espacios conquistados por los portugueses y conformando relaciones de fuerza particulares con sus habitantes. Señalaremos, finalmente, cómo esas relaciones se proyectaron en el tiempo en la nueva sociedad constituida, ya en el contexto de la gramatización del portugués vinculada a la consolidación del nuevo Estado nacional independiente, en que ese imaginario que estructuró en un primer momento la relación entre europeos e indios pasó a afectar la relación entre brasileros y brasileros, significados de acuerdo con su inscripción en el espacio (urbano/no urbano) y el dominio de esas tecnologías (letrados/iletrados).

Palabras-claves: escritura, gramática, ciudad.

${ }^{1}$ Pesquisadora do Laboratório de Estudos Urbanos - Labeurb/Nudecri e professora credenciada no Departamento de Linguística do Instituto de Estudos da Linguagem - IEL, da Unicamp. 


\section{AS REVOLUÇÕES TECNOLINGUÍSTICAS E A CIDADE}

Este texto propõe caracterizar a instrumentação das línguas, através da escrita e das gramáticas e dicionários, como uma tecnologia urbana, através de um paralelo que pode ser estabelecido entre os processos de gramatização e de urbanização. Essa é uma leitura que organiza, sob a ótica da cidade, uma série de fenômenos abordados pelo conjunto de pesquisas que integram o Programa História das Ideias Lingüísticas (HIL) ${ }^{2}$, que tem como um dos principais objetivos estudar a constituição em longo prazo das noções e conceitos que fundamentam as ciências da linguagem.

Alguns esclarecimentos sobre os pressupostos que sustentam essas pesquisas parecemnos pertinentes para melhor situar a leitura proposta. Em primeiro lugar, considera-se que uma condição necessária para que um saber científico se constitua é a escrita, o que concerne não apenas o saber linguístico como também as ciências, de modo geral: a escrita é uma tecnologia linguística sem a qual não há ciência. Essa afirmação, de Sylvain Auroux, conduz à primeira das teses centrais propostas pelo autor, a saber, a de que a invenção da escrita em finais do IV milênio antes de nossa era representou a primeira revolução tecnolinguística da humanidade (cf. Auroux 1992a). Desenvolveram-se a partir do limiar da escrita diversas tradições, milenares, de reflexão sobre a linguagem, tais como as da antiga Mesopotâmia, do Egito, da Índia, da China, da Grécia, dos árabes ${ }^{3}$. De todas elas, seria a tradição gramatical grega, tal como adotada e desenvolvida em Roma, a base a partir da qual se constituiriam as ciências da linguagem modernas.

Compreender como se deu essa passagem nos remete à segunda das teses do referido autor, que atribui à gramatização massiva operada a partir do Renascimento europeu, com base na tradição greco-latina, a segunda revolução tecnolinguística, comparável em importância para a humanidade à revolução agrária do neolítico ou à revolução industrial do século XIX (ibidem). Auroux sustenta que a descrição da diversidade das línguas do mundo a partir de uma mesma trama nocional, processo único em seu gênero ${ }^{4}$, criou uma

\footnotetext{
${ }^{2}$ Programa desenvolvido no Departamento de Linguística do IEL, Unicamp, desde a década de 1990, em parceria com instituições francesas e com a colaboração de pesquisadores de diversas instituições brasileiras e internacionais. A descrição do Programa, bem como dos projetos desenvolvidos e das publicações, pode ser encontrada no endereço: http://www.unicamp.br/iel/hil/.

O Labeurb desenvolve pesquisas vinculadas a esse Programa na linha estudos da língua, escrita e cidade, das quais destacamos a bvCLB - Biblioteca Virtual das Ciências da Linguagem no Brasil, projeto realizado desde 2005, em colaboração com a Universidade de Lausanne, Suíça, no quadro de sucessivos acordos de cooperação científica. A bvCLB é de livre acesso e está disponível no endereço http://www.labeurb.unicamp.br/ bvclb. As reflexões apresentadas neste artigo fazem parte do desenvolvimento desse projeto.

3 A escrita é uma tecnologia que objetiva a linguagem, pois permite sair da linearidade da manifestação linguageira e criar técnicas para obter uma visão simultânea, bidimensional, de fenômenos que não são naturalmente dados dessa forma (confecção de tabelas, de listas, etc.); através dessa instrumentação é possível identificar regularidades e formular uma explicação para as mesmas (cf. Auroux, ibidem; Colombat, Puech e Fournier 2010). Mas o conhecimento linguístico não é uma consequência natural da escrita, o que o desencadeia é a alteridade: a escrita, ao fixar a língua, objetiva a alteridade e a coloca diante do sujeito como um problema a ser resolvido - alteridade que pode ter múltiplas fontes, como, por exemplo, a antiguidade de um texto escrito ou palavras de origem estrangeira que se quer compreender (cf. Auroux, ibidem).

${ }^{4}$ Uma vez que as demais tradições linguísticas se limitaram à análise das línguas a partir das quais se constituíram (sânscrito, chinês, árabe...). A análise das circunstâncias históricas da Europa medieval e renascentista que explicam esse fenômeno é um objetivo central nesse programa de pesquisa.
} 
rede homogênea de comunicação que transformou profundamente as sociedades e a relação dos sujeitos com suas línguas, além de explicar as características das ciências da linguagem tal como a conhecemos hoje. $\mathrm{O}$ fato de que essa rede tenha estado centrada inicialmente na Europa, assinala o autor, deu a esta um meio de conhecimento e de domínio sobre as culturas do planeta, de forma que cada nova língua incorporada à rede, assim como cada novo canto do mundo representado pelos cartógrafos europeus, foi aumentando a eficácia dessa rede e seu desequilíbrio em benefício da Europa.

É importante destacar a concepção tecnológica de gramática e de dicionário aí esboçada e suas consequências para a definição tanto de língua como de conhecimento linguístico. A gramática não é, dessa perspectiva, a descrição de um objeto real bem delimitado que existiria enquanto tal no mundo ${ }^{5}$, de uma capacidade que estaria homogeneamente distribuída em todos os locutores de uma língua, mas de um corpo de regras e de formas que não aparecem juntas em um mesmo locutor e que nunca abrangerão o conjunto de manifestações concretas dessa língua (algo que é ainda mais evidente no caso do dicionário); a gramática e o dicionário são instrumentos que estendem a capacidade linguística do locutor, do mesmo modo que um martelo estende a capacidade do braço (cf. Auroux 1992a, 1998). Esse trabalho de instrumentação não deixa intactas as línguas, mas afeta seu funcionamento e sua "evolução", o que significa reconhecer uma estreita relação entre a prática da língua e a prática científica sobre ela (cf. Orlandi 2001, p. 11-12). Essa interferência da prática científica em seu objeto leva a considerar, ainda, que não apenas a gramática e o dicionário, mas que a própria língua, objeto dos linguistas, concebida como sistema homogêneo, com regras e fronteiras nítidas e independentes do espaço, das circunstâncias e dos locutores, é também um artefato que resulta desse mesmo trabalho tecnológico de instrumentação realizado ao longo da história ${ }^{6}$.

Mas por que chamar essas tecnologias linguísticas de urbanas, conforme propomos? A ideia surge da constatação, ao debruçar-nos sobre a constituição das ideias linguísticas, de que a história da escrita e da gramática está relacionada à história da cidade, de que os processos de gramatização que se desencadearam a partir da escrita estiveram sempre acompanhados por processos de urbanização, nas mais diferentes formas que tais processos assumiram ao longo da história, de acordo com as condições sociais, culturais e políticas muito heterogêneas em que se operaram. Esse fato recorrente nos faz voltar a atenção para uma coincidência histórica inaugural e bem conhecida, a de que escrita e cidade nascem juntas, que a revolução da escrita, como a designa Auroux, é contemporânea e indissociável dos processos políticos e econômicos que produziram a revolução urbana, expressão cunhada pelo paleontólogo Vere Gordon Childe $^{7}$, por volta dos anos 1940, para referir-se

\footnotetext{
${ }^{5}$ Como afirma Auroux (1998), no mundo só observamos sujeitos que têm certa capacidade de falar, inseridos numa rede de práticas sociais e num espaço-tempo determinado.

${ }^{6}$ A língua como sistema gramatical homogêneo é, dessa perspectiva, uma realidade imaginária, em constante tensão com o real fluido da língua, conforme distinção que estabelece Orlandi entre língua imaginária (artefato que os analistas de linguagem produzem ao longo da história, ao fixarem a língua através de normas, no âmbito das instituições) e língua fluida (enquanto língua movimento que está em mudança contínua, que vai além das normas e que não pode ser contida em arcabouços e fórmulas) (cf. Orlandi e Souza 1988, p. 34; Orlandi 2009, p. 18).

${ }^{7}$ É o mesmo autor a quem devemos a expressão revolução neolítica.
} 
à emergência dos primeiros assentamentos humanos permanentes que a historiografia reconhece como cidades.

É precisamente essa questão da permanência um ponto de intersecção, a ser destacado, entre ambas as revoluções, cuja coincidência histórica assinala o fato de que ao se fixarem em cidades, as sociedades que o fizeram fixaram também suas línguas, primeiro pela escrita, posteriormente pela gramática, limitando assim seu movimento ${ }^{8}$ - dos sujeitos nômades pela sua inscrição permanente no espaço de vida; das línguas orais, em sua variabilidade espaço-temporal, pela inscrição permanente de signos na argila, no papiro, no papel... A escrita, a gramática e o dicionário são tecnologias do registro, da permanência, que ao instrumentarem a língua permitem instrumentar também o espaço-tempo de vida, participando assim da constituição da cidade.

Além dessa coincidência histórica e das profundas transformações produzidas nas sociedades em que se operaram, é importante observar que essas revoluções vão instaurar uma memória duradoura afetada por essa ideia da permanência, em que está inscrito o imaginário de Ocidente, que significará os sujeitos de acordo com o domínio dessas tecnologias e incidirá nas relações estabelecidas tanto entre as sociedades como no interior das mesmas. Os instrumentos linguísticos são por isso, como afirma Eni Orlandi (2001), objetos históricos, que intervêm na constituição da forma das instituições e das relações sociais. Sua transferência deve ser pensada junto ao imaginário que lhes é indissociável e aos efeitos políticos que produzem. No que diz respeito à gramatização massiva a partir das grandes empresas colonizadoras renascentistas, devemos levar em conta que a Europa, junto com suas línguas e suas ideias sobre elas, exportou também suas ideias sobre o espaço, que contribuíram para o desequilíbrio das relações estabelecidas com as sociedades dos territórios conquistados.

É nosso interesse mostrar, neste texto, de que modo esse imaginário ocidental agiu na colonização no Brasil, orientando o trabalho de instrumentação das línguas e dos novos espaços descobertos pelos portugueses e conformando relações de força particulares com seus habitantes, que se projetarão no tempo na nova sociedade constituída. Faremos, antes disso, um breve percurso histórico, para trazer alguns elementos que nos permitam situar a invenção da escrita e o surgimento da gramática em Ocidente e visualizar sua relação com os processos de urbanização.

\section{A INVENÇÃO DA ESCRITA E A PRIMEIRA CIDADE}

A escrita foi criada em finais do IV milênio antes de nossa era em Uruk, na antiga Suméria, considerada a primeira sociedade urbana da história ${ }^{9}$. Os primeiros textos

${ }^{8} \mathrm{O}$ movimento é, como propomos em outros trabalhos, uma noção pertinente para compreender a especificidade da ordem do urbano (cf. Rodríguez-Alcalá 2002, 2003, 2010).

${ }^{9}$ Para a historiografia contemporânea a cidade não teve origem num único centro. Mas, de acordo com Liverani, o caso de Uruk e da Baixa Mesopotâmia é emblemático, não apenas por ser provavelmente o mais antigo de todos e o mais bem documentado, como também pelo interesse particular que suscita para o mundo ocidental: grande parte de seus elementos de civilização, afirma o autor, depois de muitos passos intermediários e nada unívocos, derivam dele (cf. Liverani 2006, p. 9-10). 
encontrados consistiam em inscrições, sobre tabuletas de argila, de signos em sua maioria pictográficos, cujo desenvolvimento daria lugar à escrita cuneiforme. Os textos eram registros administrativos e listas lexicais, escritos num sistema que por muito tempo manteria uma função mnemônica: registrava-se apenas o estritamente necessário para recordar textos que se conheciam, conhecimento prévio sem o qual eram dificilmente utilizáveis (mesmo textos literários posteriores ainda utilizariam esse sistema) (cf. Cavigneaux 1989, pp. 101, 113).

Existem registros que atestam usos anteriores e/ou com funções diferentes de signos escritos, alguns dos quais remontam ao VII milênio, ao chamado período neolítico, mas é significativo o fato de que, antes do advento da cidade, os mesmos não teriam dado lugar ao desenvolvimento de um sistema de escrita propriamente dito (cf. Liverani 2006). A escrita teria sido o resultado e a culminação da própria revolução urbana, em estreita relação com as necessidades de contabilidade e de gestão de uma estrutura política burocratizada de tipo estatal, caracterizada por fatores tais como o adensamento do habitat, a existência de índices de organização quase industrial do trabalho, a construção de arquitetura monumental (cf. Liverani 2006; Cavigneaux 1989).

Outro fato significativo é que junto com a escrita surgiram os especialistas, os escribas (neologismo da época que significava "aquele que escreve sobre as tábuas"), além de instituições como o arquivo, com o objetivo de conservar os textos para fins de contabilidade e de controles periódicos, e a escola, para a transmissão de uma técnica que logo se tornou complexa, requerendo um aprendizado difícil, e que deu lugar a uma reflexão filológica que pode ser considerada científica (cf. Liverani 2006; Cavigneaux 1989). Os escribas participavam tanto do desenvolvimento da técnica como de sua transmissão, com o auxílio das listas lexicais que seriam ainda por muitos séculos utilizadas como manuais escolares (cf. ibidem).

Esse acontecimento da emergência da cidade, indissociável do desenvolvimento de suas tecnologias e de suas instituições ${ }^{10}$, bem como dos sistemas político (o estado) e econômico que emergiram junto com ela ${ }^{11}$, constituirá um marco em determinada historiografia ocidental, estando na base de um discurso fundador, no sentido em que o

${ }^{10}$ São interessantes as observações de um historiador da cidade sobre uma questão como essa que é também objeto dos historiadores das ideias linguísticas: "A partir de suas origens, a cidade pode ser descrita como uma estrutura especialmente equipada para armazenar e transmitir os bens da civilização e suficientemente concentrada para admitir a quantidade máxima de facilidades num mínimo de espaço, mas também capaz de um alargamento estrutural que lhe permite encontrar um lugar que sirva de abrigo às necessidades mutáveis e às formas mais complexas de uma sociedade crescente e de sua herança social acumulada. A invenção de formas tais como o registro escrito, a biblioteca, o arquivo, a escola [...] constitui um dos feitos mais antigos e mais característicos da cidade." (Munford 1991, p. 38-9).

${ }^{11}$ A revolução urbana esteve condicionada pela produção e acúmulo de um excedente econômico, graças ao desenvolvimento das tecnologias agrícolas e de domesticação de animais, o que levou à estratificação social, sobretudo laboral, e à constituição de um certo mercado (cf. Childe 1936,1950; Liverani 2006). (Como lembram os historiadores da cidade, a caça e a coleta de alimentos não permitem a concentração permanente num espaço reduzido, pois sustentam menos de quatro pessoas por quilômetro quadrado, o que exige um amplo raio de ação e grande liberdade de movimento; além disso, esse tipo de economia é muito instável, estando sujeita ao acaso e à sorte, pela qual o homem "ora se banqueteia, ora passa fome".) (Munford 1991, p. 17). 
define Orlandi ${ }^{12}$, sobre a "história da humanidade". Ele é a referência básica sobre a qual se apoiam as clássicas periodizações, consideradas de validade universal, que situam as sociedades sem escrita e não urbanas fora (aquém) da história, que é identificada à história escrita (por oposição à pré-história oral), e da civilização, que pela etimologia latina remete à cidade. É em relação a esse modelo da escrita e do urbano, que se difundiria entre as sociedades do Mediterrâneo, que a cultura da Antiguidade greco-latina será instituída no imaginário de Ocidente como "o" paradigma da civilização, cuja imposição ao resto do mundo pela Europa — sua herdeira — justificará as grandes empresas expansionistas na Idade Moderna ${ }^{13}$. Vejamos alguns passos na constituição do modelo linguístico transferido a partir desse contexto urbano.

\section{O SURGIMENTO DA GRAMÁTICA E O MODELO URBANO OCIDENTAL}

O texto fundador da gramática ocidental é a Techné grammatiké, atribuída a Dionísio de Trácia, que data de finais do século II a. C. Mas, de acordo com Françoise Desbordes $(1989)^{14}$, ela é o resíduo escolar de um conjunto de ideias mais antigas sobre a linguagem que foram desenvolvendo-se progressivamente desde a própria criação do alfabeto grego, a partir do fenício, no século VIII a. C., fato contemporâneo, cabe observar, das transformações políticas e econômicas que levaram à formação da polis.

A reflexão gramatical surgiu originariamente no interior de outra disciplina, constituída no século VI a. C., que é o ancestral distante de todas as ciências da linguagem, a saber, a musiké, estudo da fala poética, dom das Musas, que era uma fala cantada. A musiké compreendia a análise de três aspectos: o ritmo, a melodia e o "falado"15. O estudo deste último aspecto, o "falado", separado do ritmo e da melodia, teria se emancipado, entre os séculos V e IV a. C., dando lugar à techné grammatiké. Esse fato teria estado relacionado às transformações do estatuto do texto escrito ocorridas por essa época. Criada provavelmente como instrumento de comércio e utilizada por muito tempo para a transcrição de textos poéticos existentes e conhecidos que se queria recordar, a escrita passou a servir

12 “O Discurso Fundador [...] não se apresenta como já definido, mas antes como uma categoria do analista a ser delimitada pelo próprio exercício da análise dos fatos que o constituem, observada sua relevância teórica. Mais especificamente, em relação à história de um país, os discursos fundadores são discursos que funcionam como referência básica no imaginário constitutivo desse país. E a nossa tarefa é mostrar como é que eles se estabilizam como referência na construção da memória nacional" (Orlandi 1993, p. 3).

${ }^{13}$ Como sintetiza um nacionalista francês das primeiras décadas do século XX, ao falar da distinção que propõe entre as sociedades em estado selvagem, as civilizações bárbaras e a Civilização plena (com "C" maiúsculo): "Essa Civilização de qualidade absoluta chamou-se somente, em seus belos dias, a Grécia. Foi Roma que a espalhou no universo, primeiro com as legiões de seus soldados e seus colonos, em seguida com os missionários da fé cristã." [Cette Civilisation tout en qualité s'appela seulement, dans ses beaux jours, la Grèce. Elle fut Rome qui la dispersa dans l'univers, d'abord avec les légions de ses soldats et des ses colons, ensuite avec les missionnaires de la foi chrétienne.] (Maurras 1937: 145, grifo nosso).

${ }^{14}$ Fundamentamos nessa autora, salvo indicação contrária, o grosso das observações a seguir sobre a história da gramática na Antiguidade greco-latina.

${ }^{15}$ Foi no quadro da musiké que começaram a organizar-se muitos dos conhecimentos que hoje dizem respeito à fonética: a classificação dos sons elementares em vogais, semivogais e consoantes; a determinação das famílias de sons em termos acústicos e de articulação (sons labiais, dentais...); a definição das propriedades das sílabas (duração, acento...). 
para a composição de textos em prosa que será preciso decifrar. Esse uso difundiu-se, levando à necessidade da alfabetização que, por sua vez, fez nascer a instituição escolar, no século V, generalizada no século seguinte. A techné grammatiké, "ciência das letras" (do grego grammata, letras, caracteres), surgiu nesse contexto como uma técnica elementar de acesso à leitura e à escrita, baseada no sistema da scriptio continua ${ }^{16}$, que era ensinada pelo grammatistés ("aquele que ensina as letras"), nome dado ao professor de escola especialista dessa técnica ${ }^{17}$.

Mas antes que aparecessem os primeiros textos que conhecemos hoje como gramáticas, a grammatiké partilhou seu interesse pela linguagem com outras disciplinas que também a tinham como objeto, como a retórica e a dialética, no quadro da reflexão desenvolvida nos textos dos grandes filósofos (Platão, Aristóteles, os estoicos). Esses textos prolongaram as análises dos poetas, dos músicos e dos grammatistés $^{18}$, mas dando-lhes um sentido diferente. A fala deixou de ser abordada através de sua relação com a poesia, a escrita ou a leitura, para ser analisada em virtude de sua capacidade de representar, corretamente ou não, o real (a verdade dialética) e de seu poder de convencimento (a eficácia retórica) ${ }^{19}$. Essas análises, que surgiram como resposta às questões colocadas pelos sofistas, deram à reflexão sobre a linguagem uma nova fisionomia.

A gramática estabeleceu um domínio próprio através de um processo de independência e de delimitações recíprocas com essas disciplinas conexas e sob o impulso determinante da filologia, cujo surgimento esteve ligado à criação da grande biblioteca de Alexandria, no século III a. C., sob iniciativa de Ptolomeu I (367 - 283 a. C.). De acordo com Baratin (1989, p. 201-2), a reunião de um número considerável de manuscritos compostos em tempos e lugares diferentes que era preciso classificar e comentar, a fim de tornar sua

${ }^{16} \mathrm{O}$ texto na Antiguidade grega apresentava-se como uma sucessão de letras, sem nenhuma forma de pontuação nem de separação de palavras, que era preciso aprender a reconhecer e a agrupar em unidades maiores (sílabas, palavras, depois enunciado completo).

${ }^{17}$ A simetria etimológica entre esses termos (grammata, grammatiké, grammatistés) constitui mais um indício da recorrência histórica da relação entre os processos de urbanização e de escolarização, através da questão da escrita e da gramática, que Claudia Pfeiffer propõe em suas pesquisas relativas a um contexto muito diferente, o da gramatização brasileira do português no século XIX.

${ }^{18}$ É no interior da reflexão filosófica sobre a linguagem que a primeira segmentação e classificação das unidades do lógos feita pela musiké e pela grammatiké (letras, sílabas) foi sendo desenvolvida. Platão acrescentou a noção de palavra e uma primeira classificação, ónoma e rhçma (nome e verbo), completando assim o esquema letra-sílaba-palavra-enunciado. Essa classificação foi reelaborada e estendida por Aristóteles e pelos estoicos e constituiu a base sobre a qual se desenvolveu o esquema das oito partes do discurso (nome, pronome, verbo, particípio, preposição, advérbio, conjunção, interjeição), que, com algumas variações, se tornou canônico para toda a produção gramatical posterior em Ocidente a partir da Techné de Dionísio de Trácia.

${ }^{19} \mathrm{O}$ surgimento da retórica, uma das disciplinas da linguagem mais antigas, esteve intimamente ligado à emergência das cidades gregas e ao sistema democrático que nelas se desenvolveu a partir de finais do século VI a. C. Independentemente de suas limitações de fato, esse sistema previa em princípio o igual direito à palavra pública a todos os cidadãos e o julgamento soberano do povo, que podia aceitar ou recusar essa fala para tomar as decisões concernentes à polis. Percebeu-se logo, porém, que nem todos tinham o mesmo poder de convencimento, o que deu lugar à elaboração, entre os séculos V e IV, das primeiras technai, inventários elementares de recursos de sedução pela palavra, ensinados pelos especialistas na arte de convencer, os sofistas. As technai adquiririam o estatuto de tratados teóricos num período um pouco posterior, com a Retórica de Aristóteles, em que o filósofo ultrapassou o estágio da simples descrição dos mecanismos eficazes da fala para examinar os princípios de sua eficácia, formulando os mecanismos do silogismo (cf. Colombat, Fournier e Puech 2010). 
leitura acessível, exigiu a produção de uma série de instrumentos técnicos, feita pelos sábios e filósofos que convergiram para esse novo centro de cultura e de atividade intelectual. Dentre esses instrumentos estava a gramática, ao lado de outros, como as coletâneas de termos dialetais, poéticos ou caídos em desuso, as monografias sobre os autores e suas dificuldades linguísticas particulares, etc. A virada do século II para século I, época em que apareceu a Techné de Dionísio de Trácia, teria representado um momento de inflexão, em que a gramática teria ultrapassado o sentido mais técnico ligado ao reconhecimento dos caracteres da escrita para passar a ser vista como a descrição do que há de sistemático na língua (ibidem).

Foi por essa época que os romanos adotaram a grammatiké grega, no quadro do processo de helenização massiva e valorizada da sociedade romana, em que o grego se tornou língua de cultura. A grammatiké era utilizada para o ensino da leitura e da escrita, a cargo de preceptores junto às grandes famílias ou de mestres de escola, que eram frequentemente de origem grega. Ela serviu de base para a gramatização do latim, operada no contexto bilíngue que caracterizou as elites romanas, particularmente os escritores. As primeiras reflexões gramaticais datam de um período anterior, mas as grandes Artes latinas foram compostas entre os séculos IV e VI d. C. Dentre elas, será a Ars minor de Donato ${ }^{20}$ o principal modelo para a gramatização posterior dos vernáculos europeus e das demais línguas do mundo.

As características do corpus de textos da Antiguidade clássica sobre a linguagem permitem falar, de acordo com Françoise Desbordes, de uma unidade da tradição grecolatina. Sua importância para as ciências da linguagem modernas reside no fato de ela ter fixado uma determinada categorização, baseada nas classes de palavras, apresentadas com seus acidentes, regras e exemplos, que ao generalizar-se como modelo unificou os padrões teóricos de análise de todas as línguas ${ }^{21}$. O Renascimento representou um momento de inflexão nesse processo. $\mathrm{O}$ aumento significativo e sem precedentes do número de línguas gramatizadas criou um corpo composto por uma diversidade crescente de línguas muito distantes entre si que ao estarem reunidas em torno de uma mesma categorização foi possível relacionar, levando a refletir sobre suas particularidades, mas também sobre o que há de comum entre elas e a formular, assim, em termos modernos a questão da generalidade relativa ao funcionamento da linguagem ${ }^{22}$.

${ }^{20}$ Aelius Donato era professor de gramática em Roma na segunda metade do século IV d. C. e teve entre seus alunos ilustres São Jerônimo, tradutor da Bíblia.

${ }^{21}$ Essas categorias estabilizaram-se muito cedo na história de Ocidente, tornando-se tão habituais que se nos apresentam como naturais, surgidas da intuição dos falantes. Elas são, entretanto, da perspectiva que assumimos, o resultado desse trabalho teórico milenar de segmentação da cadeia linguística realizado sobre as características particulares do grego e do latim, cujos passos é possível rastrear (conforme procuramos aqui indicar com os elementos históricos brevemente esboçados). A afirmação vale não somente para as categorias de palavras (outras tradições, como o árabe ou o hebraico, por exemplo, reconhecem somente três categorias, e não oito, como na gramática greco-latina), mas para a própria noção de palavra, entre outras, termo teórico de difícil aplicação para a descrição das línguas não indo-europeias (cf. Auroux 1989, p. 30). Essa visão histórica nos leva a perguntar-nos, como observam Colombat, Fournier e Puech (2010), se o sujeito chomskiano não seria mais o resultado da gramatização das línguas do que sua fonte.

${ }^{22}$ De acordo com Auroux (1992a e 1992b), a gramatização massiva criou as condições para o surgimento das duas teorias fortes sobre a linguagem, a gramática geral dos séculos XVII e XVIII e a gramática histórica e comparada do século XIX, que antecederam e prepararam as bases sobre as quais se constituiu a Linguística geral do século XX. 
A história das ciências da linguagem esteve desse modo estreitamente ligada à transferência da gramática greco-latina ${ }^{23}$. Dado que toda transferência tecnológica, como observa Auroux (1992a e 1992b), faz parte de uma transferência cultural mais ampla, devemos considerar que essa tecnologia gramatical foi transferida junto com o modelo urbano ao qual sua elaboração esteve vinculada, que foi estendendo-se progressivamente à Europa e dali aos demais continentes. A gramatização massiva no Renascimento pode ser vista, assim, como a universalização de categorias tanto linguísticas (gramaticais) como espaciais (urbanas), que são culturais e que foram naturalizadas e instituídas como modelos para todas as demais sociedades.

É preciso considerar, ao mesmo tempo, que as transferências tecnológicas não são processos lineares nem se efetuam por uma simples transmissão, mas sim a partir de gestos de reelaboração e de reinvenção determinados pelas circunstâncias culturais, sociais e políticas particulares (quem faz essas transferências, em que direção, como, com que finalidade). Por isso, se o modelo greco-latino representa um fator de unificação que permite analisar a revolução renascentista como um mesmo fenômeno, as condições históricas concretas em que ela se produziu determinarão resultados diferentes, tanto em relação às línguas como aos espaços instrumentados.

\section{A CONSTITUIÇÃO DA LÍNGUA COMUM: CIDADE E ESTADOS NACIONAIS EUROPEUS}

A gramatização massiva das línguas europeias no Renascimento esteve associada ao processo de urbanização que acompanhou o surgimento dos Estados nacionais, no contexto das profundas transformações econômicas, sociais, culturais e tecnológicas vinculadas, tais como a emergência do capitalismo mercantil, a renovação humanista do interesse pela cultura da Antiguidade clássica, a ascensão da burguesia, a Reforma e a imprensa (cf. Auroux 1992a e 1992b). Surgiu nesse contexto a necessidade de uma língua comum, diferente do latim, para a expressão das atividades intelectuais das novas elites urbanas desenvolvidas fora do domínio da Igreja (como as ligadas ao comércio), bem como para a expressão daqueles que aderiram à Reforma (que promoveu a tradução da Bíblia) (ibidem).

A questão da língua comum era um projeto postulado pelos humanistas já a partir de Dante. Em De vulgari eloquentia (1303-1304) $)^{24}$, o autor defendia a criação de uma língua ilustre diferente das línguas antigas, a partir da língua que se encontrava nas cidades e que

\footnotetext{
${ }^{23}$ Isso nos remete às considerações mais gerais de Paul Henry (1997) a propósito do papel dos instrumentos para a constituição de uma disciplina, que esta "empresta" às práticas científicas já estabelecidas e às práticas técnicas (o autor menciona, dentre estas últimas, o exemplo da balança, cuja invenção esteve ligada ao comércio e que a partir de Galileu deu lugar a uma reflexão que desembocou na teoria das balanças, parte da física). Compreender a invenção e a transferência dos instrumentos técnicos é, portanto, uma parte fundamental do trabalho do historiador das ciências, o que no caso específico das ciências da linguagem leva a refletir sobre instrumentos como a gramática e o dicionário, que estão na base das teorizações que conduziram à reflexão moderna. Para quem aborda a história das ciências da perspectiva da Análise do Discurso, um objetivo central, ainda, é compreender a relação das tecnologias e do conhecimento científico com os processos políticos que determinam o funcionamento das sociedades.

${ }^{24}$ Texto consultado em http://www.danteonline.it/
} 
era preciso fixar, pois estava marcada pela instabilidade, pela variabilidade, pela dispersão, verdadeiros entraves para a comunicação e a transmissão do saber ${ }^{25}$. Como lembra Auroux, a lentidão das comunicações nessa época, a ausência de cultura escrita e mesmo de organização política, dotava sincronicamente os vernáculos de uma variabilidade da qual temos dificilmente consciência hoje (cf. Auroux 1992b, p. 21). A elaboração de gramáticas e dicionários das principais línguas europeias pode ser vista como uma resposta a esse problema.

A gramatização foi feita a partir de um trabalho de tradução da Ars de Donato, que ao longo de toda a Idade Média havia se tornado "o" manual para o ensino do latim. Com a queda do Império romano de Ocidente, no século V, o latim tinha deixado de ser falado como primeira língua para tornar-se uma língua que era preciso aprender, uma vez que permaneceu como língua da religião, da administração e da cultura letrada, ao lado dos novos vernáculos em formação, circunscritos às práticas linguísticas cotidianas (ibidem). Os primeiros registros escritos em vernáculos estiveram vinculados à prática da catequese (cânones recomendavam o uso das línguas locais para esse fim) e à constituição progressiva da literatura. As primeiras gramáticas foram compostas entre os séculos VII e XIII, mas essa gramatização permaneceu esporádica, limitando-se a algumas poucas línguas às margens do antigo Império de Ocidente ${ }^{26}$. O processo é incomparável, quantitativa e qualitativamente, sempre de acordo com Auroux (ibidem), ao processo desencadeado em finais do século XV a partir das línguas que vão daí para frente dominar a história da Europa.

Limitar a mobilidade dos vernáculos era uma tarefa necessária para a construção da unidade política dos Estados nacionais, bem como para os projetos expansionistas empreendidos por essa mesma época, em relação aos quais Portugal e Espanha tiveram uma posição de destaque. Como diz Antonio de Nebrija no célebre prólogo à sua Gramática de la lengua castellana, a primeira das gramáticas renascentistas de um vernáculo, "siempre la lengua fue compañera del Imperio". Sua publicação, em 1492, coincide com a unificação da nação espanhola pela conquista do Reino de Granada, último bastião sob domínio muçulmano na península, e com a chegada de Cristóvão Colombo à América. Se a língua continuasse "suelta y fuera de regla" como até então, observa o gramático humanista, depois de algum tempo encontrar-se-iam "tanta diferencia y diversidad: cuanta puede ser maior entre dos lenguas". A permanência do castelhano era uma necessidade, de um lado, para imortalizar a memória das façanhas do Império, evitando que ela "perezca con la lengua", ao fazer com que:

lo que agora i de aquí adelante en él se escriviere, pueda quedar en un tenor i estenderse por toda la duración de los tiempos que están por venir, como vemos que se ha hecho en la lengua griega y

\footnotetext{
${ }^{25}$ O interesse humanista pelo latim "autêntico" de Cícero ou de Virgílio, bem diferente do que tinha se tornado ao longo dos séculos durante os quais foi a língua veicular da atividade científica, pode ter contribuído para essa consciência de que as línguas estão submetidas a mudanças, já que o próprio latim, percebido até então como o espaço da regularidade e da estabilidade, face ao esfacelamento e à instabilidade dos vernáculos, havia podido mudar e "degradar-se" (Colombat, Fournier e Puech 2010).

${ }^{26}$ Os primeiros vernáculos gramatizados foram o irlandês e o islandês entre os séculos VII e XII; o galês no século XIII; o francês nas ilhas britânicas, após a conquista normanda, no final do século XIII (o texto mais conhecido, o Donat Barton, é mais tardio, de 1409) (cf. Auroux 1992a e 1992b).
} 
latina, las cuales, por aver estado debaxo de arte, aunque sobre ellas han passado muchos siglos, todavía quedan en una uniformidad.

De outro lado, para impor as leis aos povos conquistados:

El tercero provecho deste mi trabajo puede ser aquel: [...] Que después que vuestra Alteza metiesse debaxo de su iugo muchos pueblos bárbaros y naciones de peregrinas lenguas: y con el vencimiento aquellos tenían necessidad de recebir las leies: quel vencedor pone al vencido y con ellas nuestra lengua:

A realização deste último objetivo, porém, encontrou dificuldades durante um primeiro período, fazendo com que esses Impérios coloniais adotassem inicialmente uma postura "pragmática" de tolerância em relação às línguas das sociedades conquistadas. Foram essas as circunstâncias que levaram à gramatização das línguas indígenas no Brasil, num processo de transformação das línguas e dos espaços em direção do modelo ocidental desencadeado pela colonização portuguesa.

\section{A GRAMATIZAÇÃO DAS LÍNGUAS E A CONSTITUIÇÃO DOS ESPAÇOS COLONIAIS}

\subsection{Línguas e Aldeias Indígenas: A Instauração de uma Ordem Urbana}

A gramatização das línguas ameríndias nos domínios portugueses foi realizada por missionários jesuítas com o objetivo de evangelizar as sociedades locais, pilar para a imposição do controle político sobre elas. O trabalho linguístico foi iniciado em 1549, data da chegada da Companhia de Jesus a esses territórios, e teve como foco principal o tupi. A produção de gramáticas, dicionários e catecismos ${ }^{27}$ coincidiu com a fundação de instituições de ensino em diversos núcleos urbanos ${ }^{28}$ e esteve associada à implantação da política dos aldeamentos indígenas, paralelos às vilas e cidades portuguesas.

Essas circunstâncias permitem compreender algumas das especificidades do trabalho linguístico que participou da constituição desse espaço colonial particular, quando confrontado com aquele realizado nos espaços nacionais europeus, conforme distinção proposta por Nunes (2006). Se a instituição das línguas nacionais na Europa também se operou através de processos coercitivos sobre grupos heterogêneos e de diferentes línguas que foram submetidos ao poder centralizado do Estado, o projeto político não foi o mesmo que aquele em relação às sociedades dos territórios ultramarinos. E uma diferença fundamental, em nosso entender, diz respeito à referida questão da língua comum e do

${ }^{27}$ Além da primeira gramática, a Arte da língua mais falada na costa do Brasil, de José de Anchieta (1595), podemos mencionar o Vocabulário na Língua Brasílica (manuscrito anônimo, uma de cujas versões é datada de 1621, de acordo com Ayrosa 1938); a Arte da Língua Brasílica, de Luís Figueira (1621); o Dicionário Português-Brasiliano, anônimo (1795); o Catecismo na Língua Brasílica, de Antônio de Araújo (1618); o Compêndio da Doutrina Cristã, de João Felipe Bettendorff (1678).

${ }^{28}$ Escolas foram fundadas em Salvador (1549), São Vicente (1550), Piratininga (1554), Rio de Janeiro (1573) e norte do país (Pernambuco, Ceará, Maranhão e Pará), em finais do século XVI e inícios do século XVII. 
espaço de civilidade produzido pela emergência da burguesia, que determinou a gramatização nas nações europeias em formação. A gramatização das línguas indígenas nos domínios portugueses, assim como a de outras línguas coloniais, não foi feita pelos locutores da língua mas por europeus ${ }^{29}$, que não visavam com isso criar uma língua comum com os índios, enquanto base de convergência de uma unidade política constituída com eles. A língua dessa unidade política foi desde o início o português, apesar de seu caráter minoritário, em termos numéricos, durante todo um primeiro período da história colonial, mesmo entre os não índios. O trabalho linguístico realizado teve o objetivo utilitário de possibilitar o contato com os índios e catequizá-los, e não dignificar a língua enquanto elemento de uma cultura valorizada que se buscava preservar mas, precisamente, substituir, por ser considerada inferior.

Essa divergência ou disjunção fundante vai imprimir-se de diferentes modos nos instrumentos linguísticos e na heterogeneidade dos espaços produzidos, bem como determinar o papel central que a religião desempenhou no contexto colonial. Se a questão religiosa não esteve ausente na constituição das línguas e dos espaços territoriais do Ocidente cristão ${ }^{30}$, os fatores decisivos para a gramatização na Europa estiveram ligados principalmente ao declínio do poder da Igreja na sociedade e à constituição desse novo modelo de civilidade fundamentado na escrita e na ideologia jurídica característica dos Estados nacionais. Nos territórios conquistados a religião foi, pelo contrário, o elemento principal para promover mecanismos de identificação dos índios com um modelo que não era o do cidadão burguês — associado a um ideal, embora contraditório, de autonomia e de liberdade ${ }^{31}$ — mas de indivíduos que por sua incapacidade deviam subordinar-se aos europeus e permanecer sob sua tutela.

${ }^{29}$ Tratou-se de um processo de exogramatização e não de endogramatização (como foi o caso dos vernáculos europeus, do latim ou do grego), conforme distinção proposta por Auroux (1992a).

${ }^{30}$ Além do referido impacto da Reforma para a gramatização das línguas no contexto renascentista, não podemos esquecer-nos do papel desempenhado pela religião já bem antes disso no desenho dos contornos da Europa e das nações europeias que foi efetuando-se ao longo da Idade Média, através da luta contra o Islã e da perseguição aos judeus. Devemos ter presentes não somente as políticas de cruzada e de expansão territorial para defender as fronteiras externas do avanço dos Impérios infiéis de Oriente (os navegantes portugueses tiveram nisso um papel decisivo), como também as políticas de unificação interna fundamentadas na conversão (que incluíam o batismo forçado) e/ou expulsão de judeus e muçulmanos dos territórios europeus. Língua e religião estiveram unidas nesses processos de legitimação territorial e política em virtude da necessidade da catequese, um dos fatores que determinaram o surgimento da escrita em vernáculos, como mencionado. A questão era ainda no século XVI um problema premente para a Espanha (à diferença de Portugal, que já o tinha resolvido no século XIII), pois tinha que integrar à unidade do nascente Estado uma população de língua e religião diferentes (os mouriscos) após a recente conquista de Granada. Respondeu a essa necessidade política a elaboração da primeira gramática do árabe dialetal, a Arte para ligerame[n]te saber la le[n]gua arauiga, do frade Pedro de Alcalá, da Ordem dos jerônimos, publicada em 1505, junto com um dicionário e um catecismo, no contexto de uma política que tem muitos pontos de intersecção, que ainda merecem um estudo aprofundado, com a política em relação às sociedades ameríndias. (A memória dessas "raízes cristãs" da Europa não deixa, aliás, de ressoar até hoje, notadamente na reafirmação da "identidade europeia" frente aos fluxos migratórios de populações islâmicas, em particular, com um sentido claramente xenófobo.)

${ }^{31}$ Essa forma jurídica que corresponde ao cidadão moderno das sociedades ocidentais, caracterizado pela contradição de ser livre mas estar sujeito às leis do Estado, é diferente quando confrontada, por exemplo, à forma religiosa do sujeito medieval, para quem a ideia de submissão era mais explícita. Essa concepção histórica de sujeito, que tem como base as formulações de Louis Althusser, é central na Análise do Discurso na explicação do funcionamento da linguagem, sendo desenvolvida, principalmente, a partir dos trabalhos de Michel Pêcheux e de Claudine Haroche. 
Catequizar tornou-se assim, nos espaços coloniais, sinônimo de civilizar, base da estratégia política em relação aos índios. Como afirma o historiador da Companhia de Jesus Serafim Leite (1890 - 1969): "na selva, a primeira condição de êxito é a de impor-se aos Índios para os persuadir a iniciar a aprendizagem da catequese, isto é, da civilização" (Leite 1960, p. 312, grifo nosso). O que no caso das sociedades orais e seminômades encontradas pelos portugueses nos territórios americanos exigia a dupla tarefa de, ao mesmo tempo, fixar a língua — para traduzir a doutrina — e fixar o índio — para doutriná-lo —, pois

como cristianizar de maneira efetiva os Índios dispersos nos matos sem garantia alguma de serem achados no mesmo sítio uma semana depois para continuar a doutrina? Obstáculos, que a autoridade do Estado tinha de eliminar para a obra da civilização e da conversão [...]. (Leite 1960, p. 27)

Sem desconsiderar a distância dos processos de espacialização promovidos nesse contexto em relação ao modelo europeu, podemos dizer que o esforço nesse momento inaugural da colonização foi instaurar uma ordem urbana assentada sobre uma ideia de permanência — dos sujeitos e da língua - inexistente para os índios. O gesto primeiro era, tomando emprestadas as palavras do Pe. Manuel de Nóbrega (1517 - 1570), "fazê-los viver quietos" (Nóbrega 1955, p. 156-157). Os padres sentiam, diz S. Leite,

a necessidade absoluta de fixar os Índios ao solo para ganharem amor à terra, hábitos de trabalho, e os poderem catequizar.

O Colégio de Piratininga foi, na Capitania de S. Vicente, o grande núcleo fixador, formando-se à sua roda uma série de Aldeias, que vieram a ser mais tarde a melhor defesa de S. Paulo. (2004, p. 302 , grifos nossos)

Um dos principais empecilhos nessa empresa era a falta de Estado: como os índios não tinham Rei era "difícil assentar coisa fixa", fazendo com que se mudassem continuamente e permanecessem dispersos ${ }^{32}$, como lemos, entre outras, numa carta do Pe. Luis de Grã (1523 - 1609):

O que maior dificuldade nos faz é a mudança contínua desta gente, que não atura em um lugar senão muito pouco. [...] O pior é que não se mudam juntos senão espargidos. Isto faz que seja necessário gastar o tempo com pouca gente; e esta, quando se gastaram três ou quatro anos com ela, muda-se e perde tudo, porque não é gente que perseverar, se os deixam; e os moços espargidos seguem a seus pais. (apud Leite 2004, p. 302, grifos nossos).

E, “dispersos pelo sertão", observa Serafim Leite, "os Índios nem se purificariam de superstições, nem deixariam de se guerrear e comer uns aos outros"; era preciso "modificar o seu sistema social e econômico" para poder "fixar caçadores e pescadores andarilhos" 33 (Leite 2004, p. 42-3).

${ }^{32}$ É interessante a associação feita nesses documentos entre nomadismo e dispersão, que indica que a questão da permanência (movimento) na definição da ordem urbana é indissociável da questão da concentração (quantidade) proposta por Orlandi (1999, 2004): a cidade é, de acordo com essa autora, um espaço caracterizado pela existência de "muito, do mesmo, no mesmo lugar" (cf. Rodríguez-Alcalá 2003).

${ }^{33}$ Leite retoma nessa passagem palavras de Jorge Lima, de seu livro Anchieta (Rio de Janeiro: Civilização Brasileira, 1934). A referência é, como podemos ver, a economia de subsistência das sociedades indígenas, 
Essa mobilidade dos índios, associada à "falta de Rei”, desmanchava o trabalho civilizatório/catequético dos missionários, exigindo-lhes um permanente recomeço (como no mito de Sísifo). O Pe. José de Anchieta (1534 - 1597) queixava-se de perder o "fruto da catequese", ou parte dele, "pela instabilidade dos índios, e que eles, ao retirarem-se para outros sítios, entregues a si-próprios, voltavam aos costumes antigos" (cf. Leite 2004, p. 303). O Pe. Juan de Azpilcueta (1522-3 - 1557) justificava em virtude dessa "mudança imprevista" dos índios sua negativa a ministrar-lhes o batismo:

\begin{abstract}
Allende de otras particulares razones, dos principales me convidan a no les administrar, que son, allende de no tener rey a quien ovedezcan, de no seren sus casas fixas, de tal manera que las mudan o se mudan ellos y quando quieren; specialmente cada anno las mudan las Aldeas, y antes, si alguno se emborracha o se enoja, porque entonces no hazen más que tomaren un tizón de fuego y quemaren sus casas, y dellas salta a las otras por seren de palma, por donde se quema toda la Aldea [...]. Y así se mudan quando hombre menos piensa, como a mi muchas veces acontesce en mis Aldeas [...]. (Carta de 28 de março de 1550 aos Padres e Irmãos de Coimbra, Baia, apud Leite 1954, p. 177-187, grifos nossos)
\end{abstract}

\title{
Solicitava por isso o missionário
}

que se funde una casa para doctrina de tales almas, pues sus casas son tan mudables, que lo que les enseño a los hijos, desmanchan los padres con sus perversas malicias y costumbres, llebándolos adonde quieren y a ellos más agrada. (ibidem, grifos nossos).

A mobilidade das línguas, por sua vez, era sinal de confusão de ideias, como se depreende das palavras do Pe. Fernão Cardim (1548-9 - 1625): "Este gentio parece que não tem conhecimento do principio do Mundo, do diluvio parece que tem alguma noticia, mas como não tem escripturas, nem caracteres, a tal noticia é escura e confusa" (Cardim /1584/ 1939, p. 142). Uma vez escrita e "reduzida à arte", a língua surgiu "uniformizada e ordenada, fácil, elegante, suave e copiosa", apta para traduzir as "verdades da fé" e as orações (ibidem, p. 194, apud Leite 1957, p. 548-9).

Vemos como nesses discursos da colonização, tanto dos documentos da época como de historiadores posteriores, é atualizada essa memória da permanência do Ocidente cristão e de seu modelo de civilização assentado sobre os pilares escrita - cidade - estado e

muito recorrente na caracterização do estado selvagem dessas sociedades que não desenvolveram um mercado, como lemos também na seguinte passagem de um historiador do século XIX sobre os índios guaicurus: "É a nação guaycurú errante como todas as outras nações selvagens que não cultivam a terra nem permutam com os outros povos seus gêneros e fructos" (Francisco Rodrigues do Prado, "História dos índios cavaleiros ou da nação guaycuru", Revista do Instituto Histórico e Geográfico Brasileiro, 1839, p. 21). A questão do comércio aparece, ainda, no $\$ 3$ do Diretório dos Índios (1757), instrumento jurídico da política pombalina (voltaremos a ele mais adiante), no qual é apresentado como requisito "temporal" para a civilização: "Não se podendo negar, que os índios deste Estado se conservaram até agora na mesma barbaridade (...) não só privados do verdadeiro conhecimento dos adoráveis mistérios da nossa Sagrada Religião, mas até das mesmas conveniências Temporais, que só se podem conseguir pelos meios da civilidade, da Cultura, e do Comércio: E sendo evidente, que as paternais providências de Nosso Augusto Soberano, se dirigem unicamente a cristianizar, e civilizar estes até agora infelizes, e miseráveis Povos [...]". O comércio é, de acordo com o Diretório (§ 36), o "meio mais eficaz" dentre os que "podem conduzir qualquer República a uma completa felicidade", porque ele "enriquece os Povos, civiliza as Nações, e consequentemente constitui poderosas as Monarquias" (o grifo é nosso). 
condicionado por determinado sistema econômico. Frente a esse imaginário, as sociedades orais, seminômades, sem estado e com uma economia de subsistência baseada na caça e na coleta representaram um Outro radical, cujas instituições culturais, políticas e econômicas não foram nem mesmo reconhecidas enquanto tais: os índios eram para os ocidentais uma tabula rasa, uma "cera virgem" a ser moldada por um trabalho que devia começar "de zero" - devia, antes de mais nada, começar por assentá-los, com as exigências tecnológicas (dentre as quais as linguísticas) que isso envolvia.

É interessante observar que os elementos que sustentam esse projeto civilizatório cristianizar os índios, gramatizar a língua, urbanizar o espaço - estão reunidos na confluência de sentidos em torno do termo redução, muito frequente nos documentos da época e utilizado na célebre experiência realizada pelos jesuítas a partir do século XVII na então Província Jesuítica do Paraguai (que na época compreendia o sul do atual território brasileiro). Ele designava, ao mesmo tempo, a redução das almas "à fé", da língua "à escrita e à Arte" e do índio a "vida humana e civilizada" em povoados permanentes chamados, precisamente, de reduções, como nos conta o padre jesuíta Antonio Ruiz de Montoya (1585 - 1652), autor da primeira gramática publicada de guarani:

\begin{abstract}
Llamamos reducciones a los pueblos de Indios, que uiuiendo a su antigva vsança en montes, sierras, y valles, en escondidos arroyos, en tres, quatro, o seis casas solas, separados a legua, dos, tres, y mas vnos de otros, los reduxo la diligencia de los Padres a poblaciones grandes, y a vida politica y humana, a beneficiar algodon cõ que se vistan." (Ruiz de Montoya 1639; apud Melià 1969 I, p. 90) (grifos nossos).
\end{abstract}

O trabalho de instrumentação esteve assim determinado pela adaptação do modelo gramatical e urbano europeu à realidade muito distante das línguas e dos espaços americanos, bem como pelas características do projeto político marcado por essa disjunção que referimos, apoiado na representação da incapacidade dos índios. Estes foram forçados a entrar numa nova ordem urbana, mas sem ter tido acesso às suas tecnologias: a escrita, as gramáticas e os dicionários permaneceram como instrumentos a serviço dos missionários, que mantiveram os índios iletrados ${ }^{34}$. A relação destes com o Estado ao qual foram submetidos caracterizou-se pela mediação e pela tutela exercida pelos missionários: os índios não se tornaram interlocutores das autoridades coloniais, mas foram representados por esses porta-vozes autorizados. As características dessa relação pela qual foram integrados à nova ordem política vão ecoar longamente no lugar que os índios ocupam na sociedade brasileira e no modo como as instituições do Estado, colonial e pós-colonial, lidaram com eles ao longo da história ${ }^{35}$, como mostra E. Orlandi nas diversas análises de seu livro Terra à Vista...

${ }^{34}$ Mesmo nas chamadas reduções do Paraguai, nas quais houve uma produção escrita realizada e mesmo publicada por índios, estes não se tornaram, ao que tudo indica, autores ou leitores num sentido moderno, mas mantiveram frente à escrita o estatuto de tradutores-intérpretes alfabetizados a serviço da expressão ou dos interesses políticos dos missionários (cf. Rodríguez-Alcalá e Nunes 2008; Rodríguez-Alcalá 2011b).

${ }^{35} \mathrm{O}$ estatuto constitucional que os índios têm até hoje nos dá o que pensar nesse sentido, já que são equiparados aos menores incapazes, cuja relação com o Estado é tutelada por instituições autorizadas. 


\subsection{A CONSTRUÇÃO DO PORTUGUÊS COMO LÍNGUA COMUM E A MEMÓRIA HETEROGÊNEA DO ESPAÇO BRASILEIRO}

O trabalho de instrumentação realizado pelos jesuítas foi interrompido com a publicação do Diretório dos Índios, em 3 de maio de $1757^{36}$, documento redigido pelo governador do Grão Pará e Maranhão, Francisco Xavier de Mendonça Furtado, meioirmão de Sebastião José de Carvalho e Melo, Marquês de Pombal, primeiro-ministro durante o reinado de D. José I (1750-1777). A medida fez parte do conjunto de reformas políticoadministrativas e de expansão do comércio promovidas pelo projeto iluminista pombalino, que determinaram a expulsão da Companhia de Jesus dos domínios portugueses e a supressão de sua política em relação aos índios, com o objetivo de integrá-los à "sociedade civilizada". O Diretório proibiu as línguas indígenas em prol do ensino e do uso exclusivo, em todas as situações sociais, do português, "Língua do Príncipe", como meio para "desterrar dos Povos rústicos a barbaridade de seus antigos costumes", bem como para inculcar-lhes "o afeto, a veneração, e a obediência ao mesmo Príncipe" (§ 6). Ao mesmo tempo, introduziu modificações na administração das aldeias de índios e determinou sua transformação em povoações e vilas portuguesas ( $\$ 1$ e 2 ), no quadro de uma política de repovoamento e reurbanização para a defesa do território lusitano na América propugnada pelo projeto pombalino, que também foi responsável por um novo fluxo imigratório considerável vindo de Portugal.

Esse acontecimento produziu transformações no espaço brasileiro e deslocou o foco da reflexão linguística, até então centrado nas línguas indígenas, para o português, constituindo um marco no processo que desembocaria mais tarde na gramatização brasileira, já na segunda metade do século XIX, no contexto do Estado nacional independente (cf. Orlandi e Guimarães 2001) ${ }^{37}$.

Outras intervenções político-linguísticas ao longo do século XVIII prepararam o terreno para que o português, língua da administração colonial, fosse progressivamente se consolidando também como língua majoritária da população, constituída por portugueses e seus descendentes, índios, negros e mestiços, na qual predominava o uso da língua geral, ao lado de outras línguas indígenas e africanas. Podemos mencionar, dentre essas intervenções, a fundação de inúmeras academias (mais de vinte desde 1724), com o objetivo de produzir documentos sobre o Brasil (cf. Mariani 2001).

Um impulso decisivo foi dado em inícios do século seguinte, com a instalação da Corte portuguesa no Rio de Janeiro, em 1808, que fez do Brasil a sede de todo o extenso Império português. Esse fato aprofundou o processo de urbanização e alterou a desproporção da população branca em relação à de negros e índios, graças ao contingente importante de portugueses, além de ingleses e franceses que chegaram com a Corte. Outras consequências

${ }^{36}$ Directorio, que se deve observar nas Povoaçoens dos Indios do Pará, e Maranhã̃ em quanto Sua Magestade nã̃ mandar o contrario, confirmado como lei e estendido a todo o Brasil pelo Alvará de 17 de agosto de 1758. O documento foi por nós consultado em Almeida 1997.

${ }^{37} \mathrm{O}$ trabalho desses autores, que estrutura nossa exposição a seguir, é uma referência fundamental para o estudo da gramatização brasileira do português, pois nele encontramos uma definição do fenômeno, bem como um panorama histórico geral, com os principais acontecimentos que marcaram os diferentes períodos pelos quais passou esse processo. 
importantes desse acontecimento político para o terreno da língua foram a instalação da imprensa e a fundação da Biblioteca nacional.

As primeiras obras gramaticais foram elaboradas ainda nas primeiras décadas do século XIX, mas o processo iria intensificar-se de maneira decisiva na segunda metade do século (cf. Orlandi e Guimarães 2001). O fato esteve vinculado à consolidação do Estado nacional independente de Portugal e à acelerada urbanização que acompanhou esse processo, fatores que produziram a ampliação da cultura letrada e do público leitor, a estruturação das instituições do Estado, dentre as quais a instituição escolar, que havia se iniciado com a criação do Colégio Dom Pedro II, em 1837, a partir da transformação do antigo Seminário São Joaquim. Um acontecimento decisivo foi a publicação do "Programa de Português para Exames Preparatórios", organizado por Fausto Barreto, em 1887, que teve como resposta a publicação de um grande volume de gramáticas, dicionários e outras obras que versavam em torno da questão do português falado no Brasil e reivindicavam uma autoria brasileira do conhecimento gramatical sobre ele (cf. ibidem). Para os gramáticos brasileiros, tratava-se não apenas de mostrar que se sabia a língua, mas de produzir um conhecimento sobre ela, a partir de instrumentos conceituais diferentes daqueles que serviram de base para as gramáticas portuguesas; através da construção da unidade e da legitimidade da língua falada no Brasil, pela produção de um conhecimento científico sobre ela, visava-se reafirmar a unidade e a legitimidade do próprio Estado nacional independente, frente a Portugal (cf. ibidem).

Nesse processo de construção da língua comum comparável ao operado nas nações europeias alguns séculos antes, podemos reconhecer algumas particularidades, devidas às circunstâncias de um país surgido da separação política de uma outra nação já constituída, a nação portuguesa. Um efeito fundamental disso é a memória heterogênea que, como afirma Orlandi (2002, 2005), caracteriza a identidade da língua nacional no Brasil, produzindo uma disjunção manifestada historicamente nas discussões sobre o próprio nome da língua, homônimo do nome da antiga metrópole: a língua da nova nação independente devia ser chamada de portuguesa ou de brasileira? Essa é uma questão que, como mostram diversos trabalhos (Guimarães 2004, Mariani e Souza 2000, Dias 1996), acompanhou as discussões sobre a língua nacional no Brasil nas diferentes épocas, em relação à qual os gramáticos e outros intelectuais brasileiros oscilaram sempre, nas palavras de Orlandi (2005), entre o imaginário da autonomia e do legado de Portugal — questão que, como observa a autora, não deixa de importunar até hoje.

Os gramáticos brasileiros trabalharam, assim, inseridos nessas contradições. Eles basearam-se para suas descrições, de um lado, na tradição das gramáticas portuguesas e, de outro, nas gramáticas coloniais das línguas indígenas, dado que os contatos com estas línguas, assim como com as línguas africanas, eram considerados responsáveis pelas particularidades da língua falada no Brasil. O modelo de língua adotado era o português falado nas cidades, que foi irradiando-se progressivamente e empurrando a língua geral e as demais línguas de negros e de índios às povoações do interior (cf. Orlandi 2009, p. 91). Nesse processo, o imaginário da escrita e do urbano, que afetara num primeiro momento a relação entre europeus e índios, foi deslocando-se para a relação entre brasileiros e brasileiros, significados de acordo com sua inscrição no espaço (urbano/não urbano) e com o domínio das tecnologias lingüísticas (letrados/iletrados), como se depreende de 
diversas pesquisas do Programa HIL. Poderíamos dizer que nesse período, uma vez já instaurada uma ordem urbana no espaço brasileiro, o referido imaginário passou a opor, de um lado, aqueles que vivem na cidade ou no campo, como analisa O. Payer, mostrando que estes últimos não são nunca sujeitos de enunciação, mas objetos dos quais se fala (cf. Payer 2001, entre outros); de outro lado, mesmo no interior do espaço da cidade, esse imaginário passou a situar, num extremo, o analfabeto analisado por M. Vieira nas definições do dicionário, em que quem não domina as tecnologias da escrita é representado como um sujeito intrinsecamente incapaz (cf. Silva 1996), e o sujeito urbano escolarizado, no outro extremo, que ao bem dizer a língua constrói também sua urbanidade, a legitimidade de seu lugar na cidade, como mostram os trabalhos de C. Pfeiffer (cf. Pfeiffer 2001, entre outros). As gramáticas e os dicionários funcionam como lugares em que se constrói essa imagem da cidade enquanto lugar de civilização e de escolarização, que fazem parte do imaginário do sujeito urbano, cidadão do Estado moderno, e do ideal de língua a ele associado, participando desse modo da constituição do espaço-tempo da cidade. Como afirma Nunes (2001) em relação aos dicionários:

\begin{abstract}
Ao se debruçar sobre o espaço urbano, o lexicógrafo de certo modo desenha as cidades, introduz nela os sujeitos, delimita espaços, representa as relações sociais. [...]. O dicionário funciona como um agenciador dos falares da cidade, na medida em que capta e distribui as significações que identificam espaços e sujeitos citadinos. De um lado, absorve os discursos urbanos (administrativos, científicos, literários, mediáticos). De outro, representa-os em seu interior, de modo que eles aparecem como significações da língua. (p. 101)
\end{abstract}

\title{
6. CONSIDERAÇÕES FINAIS
}

As relações entre linguagem e cidade, objeto das pesquisas na área saber urbano $e$ linguagem desenvolvida pelo LABEURB, podem ser abordadas a partir de diferentes prismas, como mostra o leque dos artigos reunidos no presente volume. Nós escolhemos pensá-la através da relação proposta entre a história da língua e do conhecimento linguístico e a história da cidade, através da produção das tecnologias - escrita, gramáticas e dicionários - que estão em sua base, idéia esboçada mais com caráter programático do que propriamente elaborada neste artigo. Não poderíamos deixar de mencionar, para concluir, uma outra tecnologia urbana que é responsável pela terceira revolução tecnolinguística, a saber, a informática (Auroux 1998), objeto das pesquisas de Cristiane Dias e Eni Orlandi, entre outras, que analisam diversos aspectos da relação entre o espaço urbano e o espaço digital. Nosso intuito aqui foi apenas ilustrar um modo de abordar a história das ciências que considera o funcionamento político das tecnologias linguísticas, através da análise de seus efeitos na constituição da forma das línguas, das sociedades e de seus espaços de vida.

\section{REFERÊNCIAS BIBLIOGRÁFICAS}

ALMEIDA, R. H. de. (1997). O diretório dos índios: um projeto de 'civilização' no Brasil do século XVIII. Brasília: Editora da UnB. 
AUROUX, S. (1998). Língua e Hiperlíngua, Línguas e Instrumentos Lingüísticos, 1. Campinas: Pontes/Programa HIL, pp. 17-30. . (1998). A Filosofia da Linguagem. Campinas: Editora da Unicamp. . (1992a). A Revolução Tecnológica da Gramatização. Campinas: Pontes.

. (1992b). Histoire des idées linguistiques. Le développement de la grammaire occidentale. Vol. II. Lièges/Bruxelas: Mardaga.

. (1989). Histoire des idées linguistiques. La naissance des métalangages en Orient et en Occident. Vol I. Lièges/Bruxelas: Mardaga.

AYROSA, P. (1938). Prefácio, Vocabulário na Língua Brasílica. São Paulo: Departamento de Cultura.

BARATIN, M. (1989). La constitution de la grammaire et de la dialectique. In: AUROUX, S. (1989). Histoire des idées linguistiques. La naissance des métalangages en Orient et en Occident. Vol I. Lièges/Bruxelas: Mardaga, pp. 186-206

CAVIGNEAUX, A. (1989). L'écriture et la réflexion linguistique em Mesopotamie. In: AUROUX, S. 1989. Histoire des idées linguistiques. La naissance des métalangages en Orient et en Occident. Vol I. Lièges/ Bruxelas: Mardaga, pp. 99-118

CHILDE, V. G. (1936). Man Makes Himself. Londres: Watts and Co. . (1950). The Urban Revolution. Town Planning Review 21, pp. 3-17.

COLOMBAT, B.; FOURNIER, J.-M. e PUECH, C. (2010). Histoire des idées sur le langage et les langues. Paris: Klincksieck.

CARDIM, F. (1584). Tratados da Terra e Gente do Brasil. (Introduções e notas de Baptista Caetano, Capistrano de Abreu e Rodolfo Garcia). São Paulo: Companhia Editora Nacional, 1939.

DESBORDES, F. (1989). La naissance de la réflexion linguistique occidentale. In: AUROUX, S. (1989). Histoire des idées linguistiques. La naissance des métalangages en Orient et en Occident. Vol I. Lièges/Bruxelas: Mardaga, pp. 149-161.

DIAS, L. F. (1996). Os sentidos do idioma nacional. Campinas: Pontes.

FEDATTO, C. P. (2011). O Saber na História da Cidade. Tese de Doutorado defendida no Departamento de Lingüística do Instituto de Estudos da Linguagem da Unicamp.

GUIMARÃES, E. R. J. (2000). Línguas de civilização e línguas de cultura. A língua nacional do Brasil. In: Barros, D.L.P. Os discursos do descobrimento. São Paulo, Edusp/Fapesp. . (2004). História da semântica, Campinas, Pontes.

. (2002). Para uma História das Ciências da Linguagem. Línguas e Instrumentos Linguísticos, 8. Campinas: Pontes/Projeto HIL.

GUIMARÃES, E. R. J. e ORLANDI, E (org.). (1996). Língua e Cidadania: O Português no Brasil. Campinas: Pontes.

HAROCHE, Cl. (1992). Querer Dizer, Fazer Dizer. São Paulo: Hucitec (Tradução de Vouloir dire, faire dire, 1984).

HENRY, P. (1997). Os Fundamentos Teóricos da "Análise Automática do Discurso" de Michel Pêcheux (1969). In: GADET, F. e HAK, T. (orgs). (1997). Por Uma Análise Automática do Discurso. Introdução à Obra de Michel Pêcheux. Campinas: Editora da Unicamp, pp. 13-38.

LEITE, S. (1956). Monumenta Brasiliae I (1538-1553). Roma: Monumenta Historica Societati Iesu. . (1957). Monumenta Brasiliae II (1553-1558). Roma: Monumenta Historica Societati Iesu. 
LEITE, S. (1958). Monumenta Brasiliae III (1558-1563). Roma: Monumenta Historica Societati Iesu. (1960). Monumenta Brasiliae IV (1563-1568). Roma: Monumenta Historica Societati Iesu. . (2004). História da Companhia de Jesus no Brasil. São Paulo: Loyola.

(1954). Cartas dos primeiros jesuítas do Brasil. 1538-1553. São Paulo/Coimbra: Comissão do IV Bicentenário da Cidade de São Paulo.

LIVERANI, M. (2006). Uruk. La primera ciudad. Barcelona: Editions Bellaterra (Tradução de Uruk, la prima città, 1998).

MARIANI, B. C. (2001). A Institucionalização da Língua, História e Cidadania no Brasil do Século XVIII: O Papel das Academias Literárias e da Política do Marquês de Pombal. In: (org.). (2001). História das Idéias Lingüísticas. Construção do Saber Metalingüístico e Constituição da Língua Nacional. Campinas: Pontes/Unemat.

MARIANI, B. C. e SOUZA, T. C. de. (2000). Questões de lusofonia, Organon, 21. Porto Alegre: Universidade Federal do Rio Grande do Sul.

MAURRAS, Ch. (1937). Mes idées politiques. Paris: Fayard.

MELIA, B. (1969). La creation d'un langage chretien dans les reductions des guarani au Paraguay. Tese de doutorado, Universidade de Strasbourg (França), 2 vols.

MUNFORD, L. (1991). A Cidade na História. Suas Origens, Transformações e Perspectivas. São Paulo, Martins Fontes, $3^{\mathrm{a}}$ ed. (Tradução de The City in History -Its Origins, Its Transformations and its Prostpects, 1961.)

NÓBREGA, M. da. (1955). Cartas do Brasil e Mais Escritos. Com Introdução e Notas Históricas e Críticas de Serafim Leite S. I. Coimbra: Universidade de Coimbra.

NUNES, J. H. (2001). O Espaço Urbano: A “Rua” e o Sentido Público. In: ORLANDI, E. (org.). (2001). Cidade Atravessada. Os Sentidos Públicos no Espaço Urbano. Campinas: Labeurb/Pontes/CNPq, pp. 101-109. (2006). Dicionários no Brasil. Análise e História do Século XVI ao Século XIX. Campinas: Pontes.

NEBRIJA, Antonio de. (1492). Gramática de la lengua castellana. Consultada em http:// www.antoniodenebrija.org/

ORLANDI, E. (2009). Língua Brasileira e Outras Histórias. Discurso sobre a Língua e Ensino no Brasil. Campinas: RG Editores.

. (2004). Cidade dos Sentidos. Campinas: RG Editores.

. (2005). A Língua Brasileira. Ciência e Cultura. 57/2, pp. 29-30.

(2002). Língua e Conhecimento Lingüístico. São Paulo: Cortez.

. (org.). (2001). História das Idéias Lingüísticas. Construção do Saber Metalingüístico e Constituição da Lingua Nacional. Campinas: Pontes/Unemat.

. (1999). N/O Limiar da Cidade. Revista Rua. Número Especial. Campinas: Nudecri/Unicamp.

(1993). Discurso Fundador. A Formação do País e a Construção da Identidade Nacional. Campinas: Pontes.

(1990). Terra à Vista. Discurso do Confronto: Velho e Novo Mundo. São Paulo/Campinas: Cortez/ Editora da Unicamp.

ORLANDI, E. e SOUZA, T. C. C. (1988). A Língua Imaginária e a Língua Fluida: Dois Métodos de Trabalho com a Linguagem. In: ORLANDI, E (org.). (1988). Política Lingüística na América Latina. Campinas: Pontes.

PAYER, M. O. (2001). O Rural no Espaço Público Urbano. In: ORLANDI, E. P. (org.). (2001). Cidade Atravessada. Os Sentidos Públicos no Espaço Urbano. Campinas: Labeurb/Pontes/CNPq. 
PÊCHEUX, M. (1999). O Papel de Memória. In: ACHARD, P. O Papel da Memória. Campinas: Pontes. . (1988). Semântica e Discurso. Uma Crítica à Afirmação do Óbvio. Campinas: Editora da Unicamp (Tradução de Les veritées de la Palice, 1975).

PFEIFFER, Claudia C. (2001). Cidade e Sujeito Escolarizado. In: ORLANDI, E. P. (org.). (2001). Cidade Atravessada. Os Sentidos Públicos no Espaço Urbano. Campinas: Labeurb/Pontes/CNPq.

RODRÍGUEZ-ALCALÁ, C. (2011a). Discurso e Cidade: A Linguagem e a Construção da "Evidência do Mundo". In: RODRIGUES, E. A., SANTOS, G. L. e CASTELLO BRANCO, L. K. A. (orgs.) (2011). Análise de Discurso: Pensando o Impensado Sempre. Uma Homenagem a Eni Orlandi. Campinas: RG. . (2011b). Apuntes para una historia de la escritura en guaraní: el estatuto y la circulación del texto escrito en las misiones jesuíticas, Señas del Paraguay. Revista Scriptura, 21-22 (P. TOVAR e M. G. DIONISI orgs.). Barcelona: Universidad de Lleida, pp. 9-32.

. (2010). Atmosphäre und Sprache in der symbolischen Produktion des städtischen Raumes: die Unterscheidung öffentlich/privat und die Wahrnehmung von Bewegung, THIBAUD, J-P. e KAZIG, R. Hg. (orgs.). Städtische Atmosphären. Bielefeld: Bielefeld.

. (2007). L'exemple dans les grammaires jésuitiques du guarani, L'exemple dans les traditions grammaticales. Langages 166 (J.-M. FOURNIER org.), pp. 112-126.

. (2003). Entre o Espaço e seus Habitantes. Notas sobre a Construção de um Glossário Discursivo da Cidade. In: Orlandi, Eni P. (org.) (2003). Para uma Enciclopédia da Cidade. Campinas: Labeurb-Nudecri/ Pontes/CNPq.

RODRÍGUEZ-ALCALÁ, C. e NUNES, J. H. (2008). Langues amerindiennes à la Renaissance: norme et exemples dans les descriptions du tupi et du guarani, Les langues du monde à la Renaissance. Histoire, Epistémologie, Langage, 30/2 (B. COLOMBAT org.), pp. 25-70.

RUIZ DE MONTOYA, A. (1639). Conquista espiritual hecha por los religiosos de la compañia de Jesus en las provinçias del Paraguay, Parana, Uruguay y Tape. Madrid: Impr. del reyno.

SILVA, M. V. da. (1998). História da Alfabetização no Brasil: A Constituição de Sentidos e do Sujeito da Escolarização. Tese de Doutorado, Instituto de Estudos da Linguagem, Unicamp. http:// www.bibliotecadigital.unicamp.br/document/?code=vtls000132179

. (1996). O dicionário e o processo de identificação do sujeito-analfabeto, GUIMARÃES, E. e ORLANDI, E. (org.). (1996). Língua e Cidadania. O Português no Brasil. Campinas: Pontes. 


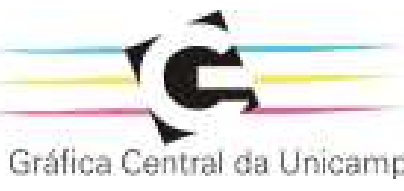

